\title{
Observation and Data Archiving System of a Superconducting Gravimeter at Syowa Station, Antarctica
}

\author{
Yuichi Aoyama1,2, Hiroshi Ikeda ${ }^{3}$, Hideaki Hayakawa', Koichiro Doi ${ }^{1,2}$, Yoichi Fukuda", \\ Kazuo Shibuya ${ }^{1}$ \\ ${ }^{1}$ National Institute of Polar Research, Tokyo, Japan \\ ${ }^{2}$ Department of Polar Science, SOKENDAI (The Graduate University for Advance Studies), Tokyo, Japan \\ ${ }^{3}$ Research Facility Center for Science and Technology, University of Tsukuba, Tsukuba, Japan \\ ${ }^{4}$ Graduate School of Science, Kyoto University, Kyoto, Japan \\ Email: aoyama@nipr.ac.jp
}

Received 11 September 2015; accepted 24 October 2015; published 28 October 2015

Copyright @ 2015 by authors and Scientific Research Publishing Inc.

This work is licensed under the Creative Commons Attribution-NonCommercial International License

(CC BY-NC).

http://creativecommons.org/licenses/by-nc/4.0/

(c) (i) (9) Open Access

\section{Abstract}

A superconducting gravimeter (SG, model TT70\#016, GWR Instruments) was deployed for the first time in Antarctica in 1992 at Syowa Station. Observations began in April 1993. Although the SG was equipped with a $10 \mathrm{~K}$ cryocooler, its liquid helium (LHe) required refilling twice a year to maintain its superconducting state. The LHe was produced by a separate helium liquefier. After continuous gravity measurement with the SG for 11 years, it was replaced by a second SG (CT\#043) with a $4 \mathrm{~K}$ cryocooler in December 2003 in order to reduce loads of person in charge for LHe production. Because the manufacturer could not supply a replacement $4 \mathrm{~K}$ cryocooler, this SG ceased measurement in November 2009. In January 2010, a new superconducting gravimeter (OSG\#058) was installed and had recorded high-quality gravity time series with data acquired every second for more than five years without interruption. Because the personal computer (PC) controlling the observation and data acquisition is connected with PCs in Japan through an Intelsat satellite communication link, we can check the status of observations in real time. It is also possible to fix remotely certain problems with the gravimeter. The observed gravity data are transferred daily to a data server in Japan. Also included in the upload are diagnostic data of the gravimeter such as the temperature of the coldhead and environmental data such as atmospheric pressure. Plots of the daily data are publicly available. The raw data with a $1 \mathrm{~s}$ sampling interval are also released to registered researchers. The released gravity time series along with the environmental data are greatly useful for investigating solid earth dynamics especially in the long period bands. We provide necessary information to use these long-range data sets. 


\section{Keywords}

\section{Superconducting Gravimeter, Remote Observation Monitoring, High Quality Data, Antarctica}

\section{Introduction}

A superconducting gravimeter (SG) is a relative gravimeter that measures temporal changes in gravity by detecting the displacement of a 1-inch niobium superconducting sphere floating in an extremely stable magnetic field created by superconducting coils. The instrument was first developed at the University of California, San Diego (e.g., [1] [2]), and then by GWR Instruments San Diego, USA. (e.g., [3]). The resolution of gravity measured by an SG reaches approximately $10^{-12}$ of the Earth's gravitational acceleration; i.e., $1 \mathrm{nGal}=10^{-11} \mathrm{~m} / \mathrm{s}^{2}$. This is equivalent to a $0.003 \mathrm{~mm}$ change in bedrock height.

Figure 1(a) shows the location of the geodesy facilities at Syowa Station on East Ongul Island, about $4 \mathrm{~km}$ from the Antarctic mainland. The island is located far from the nearest plate boundary $(>1000 \mathrm{~km})$ and experiences little seismic activity, making the site tectonically stable. The Gravity Observation Hut (GOH) was constructed in February 1991 by the 32nd Japanese Antarctic Research Expedition (JARE-32). The GOH has a marble base with an International Absolute Gravity Basestation Network Category A [IAGBN(A)] brass marker and a pier to support the SG. A detailed site information log in the format of the IAGBN Working Group SSG3.87 recommendation [4] is shown in Figure 1(b) (from [5]).

Together with precise geometric observations by Very Long Baseline Interferometry (VLBI), the Global Navigation Satellite System/Global Positioning System (GNSS/GPS), and Doppler Orbitography and Radio-positioning by Satellites (DORIS), precise geodynamic measurements by an SG under the framework of the Global Geodynamics Project (GGP; [6]) and an absolute gravimeter (AG) will make Syowa Station a unique site in the Southern Hemisphere for the future Global Geodetic Observing System (GGOS) station network (e.g., [7]), although the Satellite Laser Ranging (SLR) facility is not installed at present.

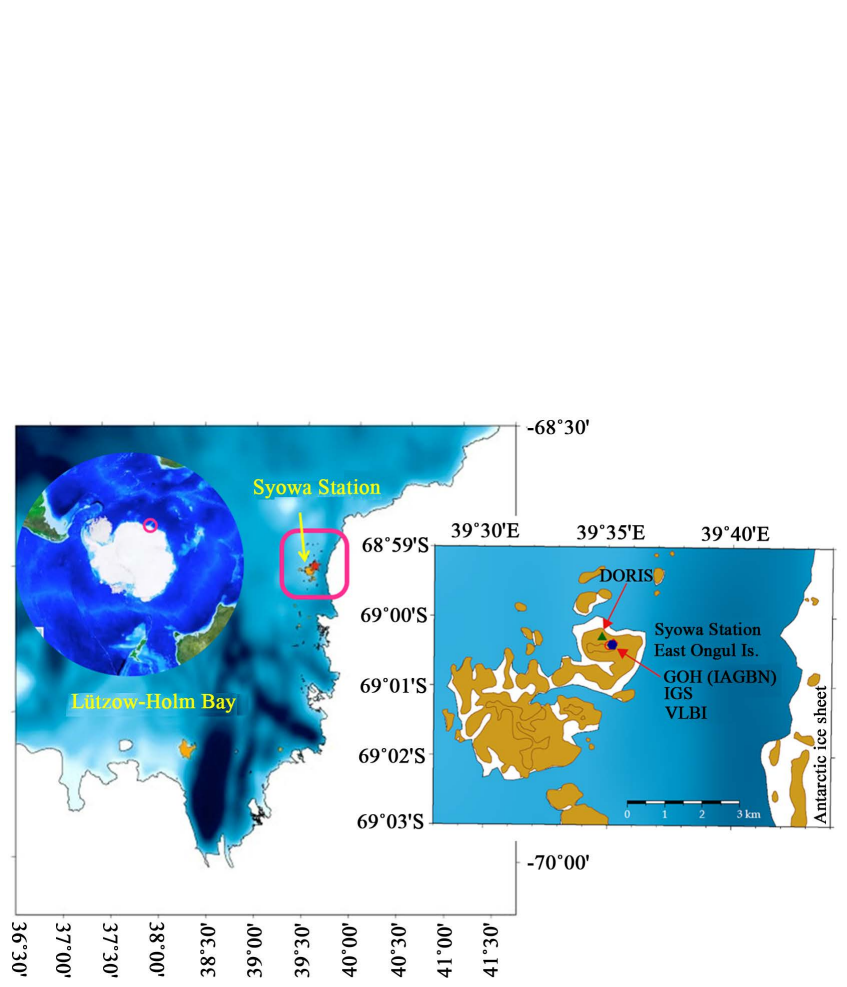

(a)

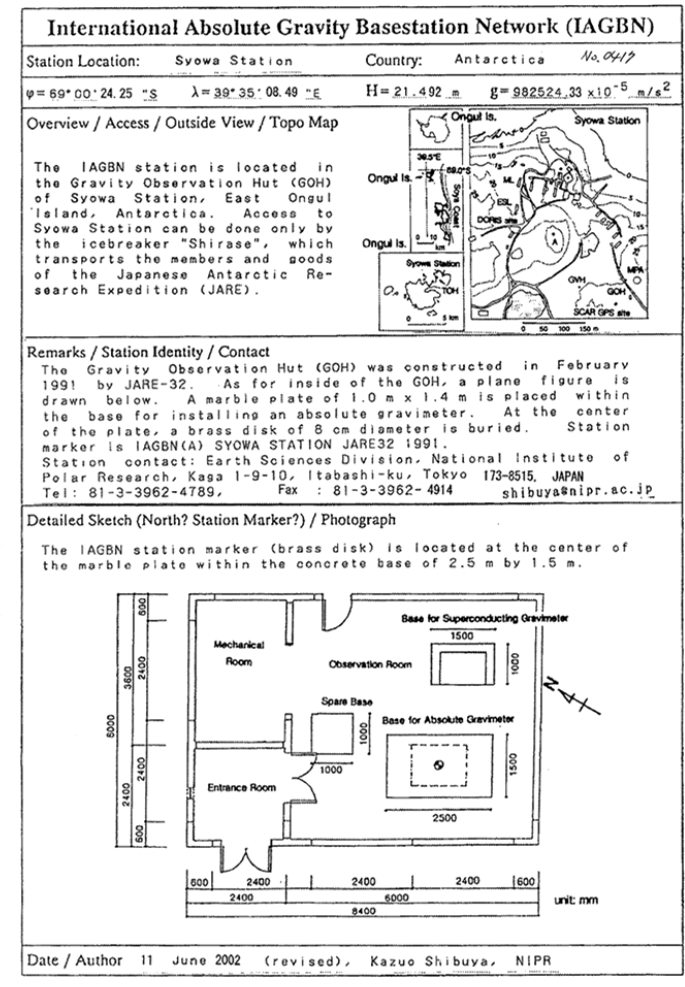

(b)

Figure 1. (a) Location of Syowa Station; (b) Site log information of IAGBN (A) in Syowa Station. 
Because GOH in Syowa Station is constructed on very stable bedrock without artificial ground noises, we have been obtaining very precise temporal gravity change for more than 20 years. Here, we will provide information about SGs used for the continuous gravity observation, their observing system, the accuracy of data obtained from the SGs, how to access the released SGs' data, and their data format, in order to encourage the use of these data sets for investigating various geodynamics such as the earth tides, effects of atmospheric, oceanic and cryospheric mass redistribution, polar motion, earth's free oscillation and so on.

\section{History of SG Observations at Syowa Station}

The installation of the first SG began in December 1992, and observations have continued for the subsequent 22 years with occasional instrument upgrades. Figure 2 outlines the configuration of the currently operating system. An SG basically consists of two components: 1) the gravimeter sensing unit, which includes the superconducting magnets, the niobium gravity sensing sphere (NB), circuitry for energizing the coils to levitate the NB, temperature control circuitry, and magnetic shielding; and 2) the liquid helium dewar and refrigeration system that keeps the gravimeter sensing unit close to $4.2 \mathrm{~K}$ to maintain its superconducting state. The improvements over the years have mostly been to component 2) to improve the capability of the cryocooler.

\subsection{TT-70\#016 (Type-I SG)}

Continuous gravity measurements by the TT70\#016 started on March 22, 1993. However, the initial data collected until the end of July 1993 were strongly disturbed by the test running of instruments, and were thus not published. Although the attached cryocooler could keep the liquid helium (LHe) reservoir (i.e., a 200 liter dewar) at $10 \mathrm{~K}$, it could not prevent the evaporation/escape of the LHe because the boiling temperature of LHe is $4.2 \mathrm{~K}$. The system required a water-circulating chiller to maintain a stable operating temperature during observation. Figure 3 shows an overview of the TT70\#016 at April 2, 1993.

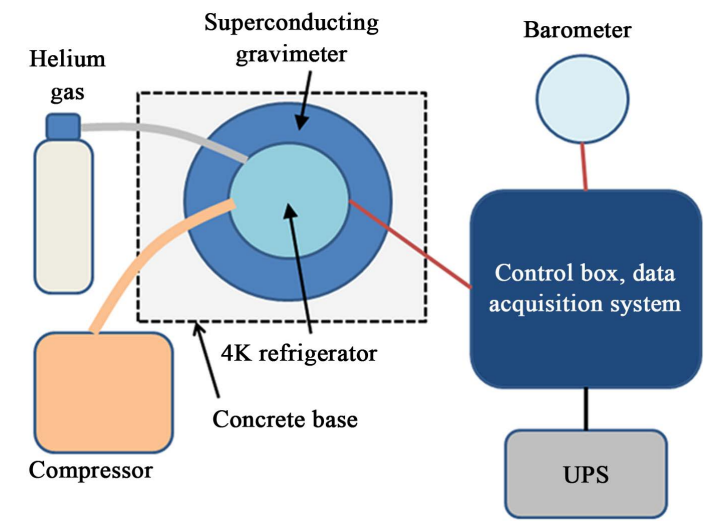

Figure 2. Horizontal projection of the system configuration.

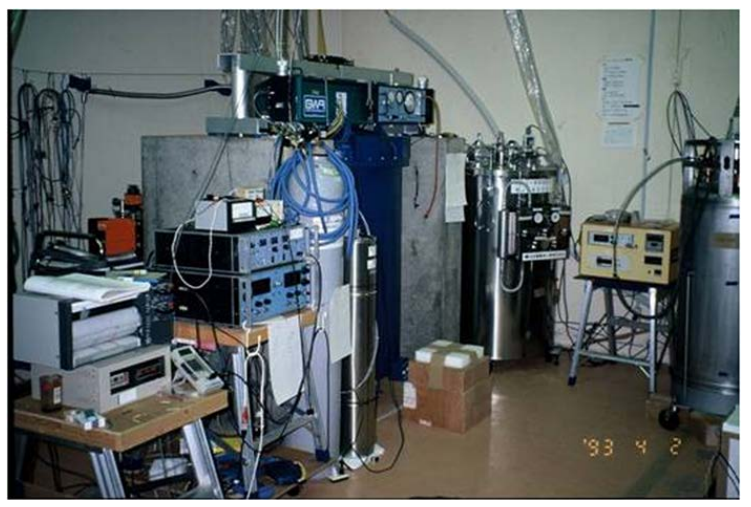

Figure 3. Overview of the TT-70 \#016 at the start of data recording. 
A separate helium liquefier produced LHe from gaseous He, and the dewar needed refilling twice a year. The semiannual refilling (i.e., June and December) introduced artificial noise to the SG records for one month following the refilling.

Parallel observations with an AG (model FG5\#203) was conducted to obtain a scale factor necessary to convert the output voltage (V) from the SG into a gravity value in $\mu \mathrm{Gal}$ units $\left(1 \mu \mathrm{Gal}=10^{-8} \mathrm{~m} / \mathrm{s}^{2}\right)$. The obtained scale factor was $-58.165 \pm 0.061 \mu \mathrm{Gal} / \mathrm{V}$ with an accuracy of $\sim 0.1 \%$ [8].

Observations with the TT-70\#016 lasted 10 years (1993-2003). Toward the end of this period, the tilt balancer was suspected to have been broken on January 16, 2001. Observations without tilt compensation began on April 5, 2001 and continued until January 4, 2002, although the problem was fixed on July 25, 2001. Iwano and Fukuda (2004) [9] analyzed the influence of the breakage on measurements by comparing the noise levels of the thermal leveler with and without the tilt compensation system. There was no other significant change in the system configuration throughout the rest of the period of operation.

During the 10 years of operation of the TT70\#016, data were sometimes lost owing to power failure in addition to the intermittent disturbance during LHe refilling (as mentioned above). Therefore, we archived detailed maintenance logs of each expedition (JARE-33 through JARE-42) in CD-ROMs [10], together with one-month data files of $2 \mathrm{~s}$ interval sampling (August 1993-December 1999) and $1 \mathrm{~s}$ interval sampling (April 1999-November 2003). The raw data files are published and accessible from the Information System and Data Center (ISDC), GFZ-Potsdam [11] and the National Institute of Polar Research (NIPR) server [12].

\section{2. СT\#043 (Type-II SG)}

The TT70\#016 SG was replaced in December 2003 by a type-II SG (CT\#043) with a 4 K cryocooler in order to reduce loads of person in charge for LHe production [13], [14]. Full replacement came after five months' parallel observation (June 16, 2003-November 6, 2003) by both SGs. The new SG could only be fitted to the existing pier without a tilt balancer, and its left-right weight balance was insufficient due to the unbalanced design of the tripod. The vertical alignment of CT\#043 then became unstable, which introduced sporadic or lasting noise during or after exchange of the coldhead. Figure 4 shows an overview of CT\#043 before and after being placed at the pier site.

We expected CT\#043, with an improved irregular component, to produce less noise than the old SG it replaced. Figure 5 (reproduced from [13]) compares the decomposed tidal time series by Bayesian Tidal Analysis Program-Grouping Model: BAYTAP-G [15] for 35 days during the period of parallel running (from August 1, 2003 through September 4, 2003). The random noise level $( \pm 1 \mu \mathrm{Gal})$ of CT\#043 was about one third that of TT70\#016, ( $\pm 3 \mu \mathrm{Gal})$. This improvement was attributed to the new diaphragm between the dewar side flange and the coldhead side flange [16], which isolated transmission of vibrational noise from the piston of the coldhead. However, the resultant instrumental drift $(+239 \mu \mathrm{Gal} /$ year $)$ became one order of magnitude worse than that

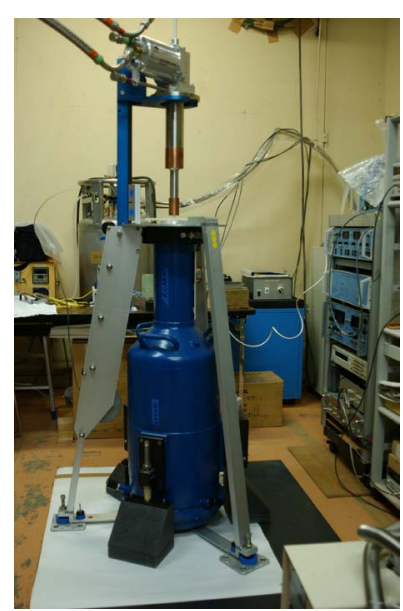

(a)

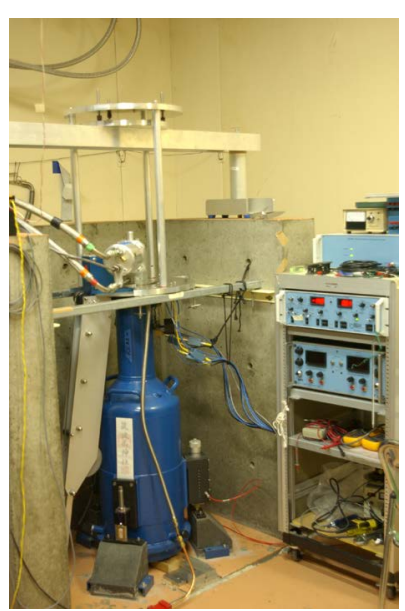

(b)

Figure 4. Overview of the CT \#043 (a) before and (b) after being placed at the pier site. 


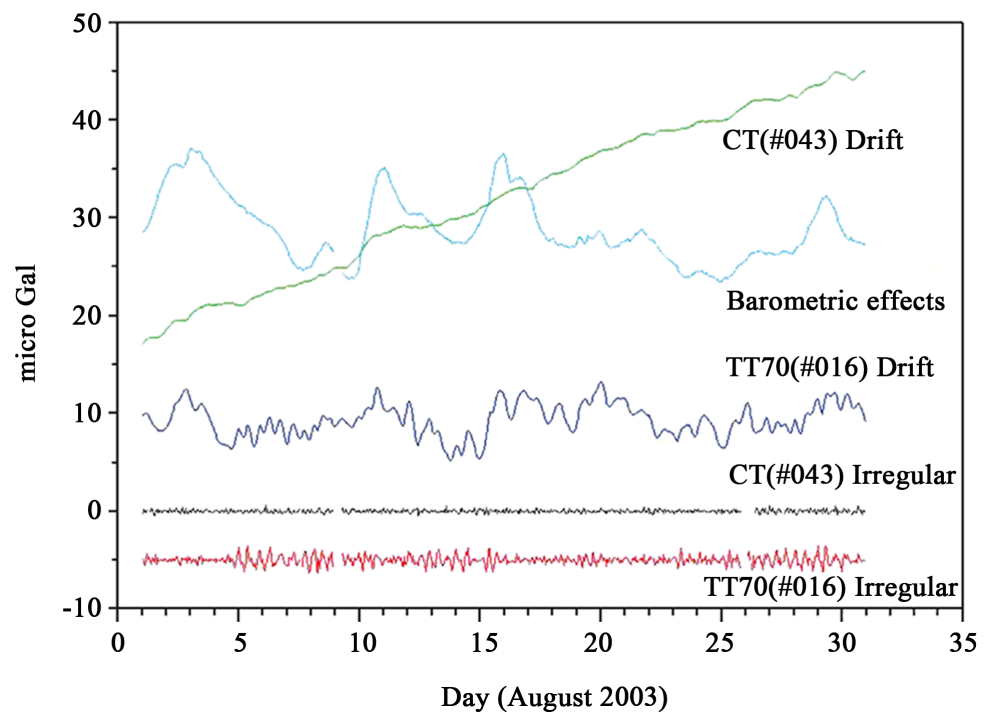

Figure 5. Comparison of decomposed tidal time series for the period of parallel running from August 1, 2003 through September 4, 2003 (35 days).

of TT70\#016 ( $-15 \mu \mathrm{Gal} /$ year). We do not know the cause of this degradation; however, it is fortunate that the drift rate (after the initial stage) showed a linear relationship to elapse time.

The CT\#043 SG was equipped with a $4 \mathrm{~K}$ cryocooler that allowed gaseous helium to liquefy in the dewar of the gravimeter, and thus a separate liquefier system was not needed. Although the cryocooler ran without problems for more than 2 years, a replacement was not available when needed because the manufacturer (Leybolt) had ceased production. Observations with the CT\#043 continued until November 2009, with data sampling every $1 \mathrm{~s}$ through a GGP1 filter [17]. Its configuration did not require a water circulating chiller.

The scale factor for CT\#043 was determined as $-59.461 \pm 0.079 \mu \mathrm{Gal} / \mathrm{V}$ by simultaneous observation with the FG5\#210 AG in January 2004 [18].

Observations by the CT\#043 lasted almost 7 years, from December 2003 to December 2009. Its archived daily data files are available in monthly directories (January 2003-December 2008) accessible online [12]. The data collected in 2009 were severely contaminated by noise from the coldhead vibration, and are thus not included in the archive.

\subsection{OSG\#058 (Type-III SG)}

The CT\#043 SG was replaced by a new type-III OSG\#058 during December 2009 and January 2010 (Figure 6; [16]). The problem of large drift shown in the records of CT\#043 was solved, and the output gravity signal appears almost free from instrumental drift (this is described below).

The gravity sensor is housed in a LHe dewar equipped with a $4 \mathrm{~K}$ refrigeration system (Sumitomo Heavy Industries). The manufacturer recommended maintenance of the coldhead every $10,000 \mathrm{~h}$, but in practice no malfunction has occurred with it running for 22,000 - 26,000 h between replacements. The problem of air-icing experienced by the TT70\#016 and CT\#043 during replacement of the coldhead could be avoided by blowing gaseous helium around the neck of the LHe dewar. A supply of gaseous helium was not necessary, except at times of incidents such as coldhead replacement or failure of the electric power supply.

The conversion factor of the OSG\#058 was determined to be $-73.8226 \pm 0.053 \mu \mathrm{Gal} / \mathrm{V}$ by parallel observation with the FG5\#203 AG in January 2010 [19].

The main improvements in the OSG\#058 over the systems it replaced are environment control and status monitoring. Its output signals are recorded at $1 \mathrm{~s}$ intervals by a PC through the GGP1 filter. Status data such as temperature and pressure in the dewar, and also environmental data such as atmospheric pressure and room temperature, are also recorded. The data acquisition system is stored in a temperature-regulated box to suppress the influence of environmental changes (see Figure 6). Further details are given on the website of GWR Instruments at [20]. 


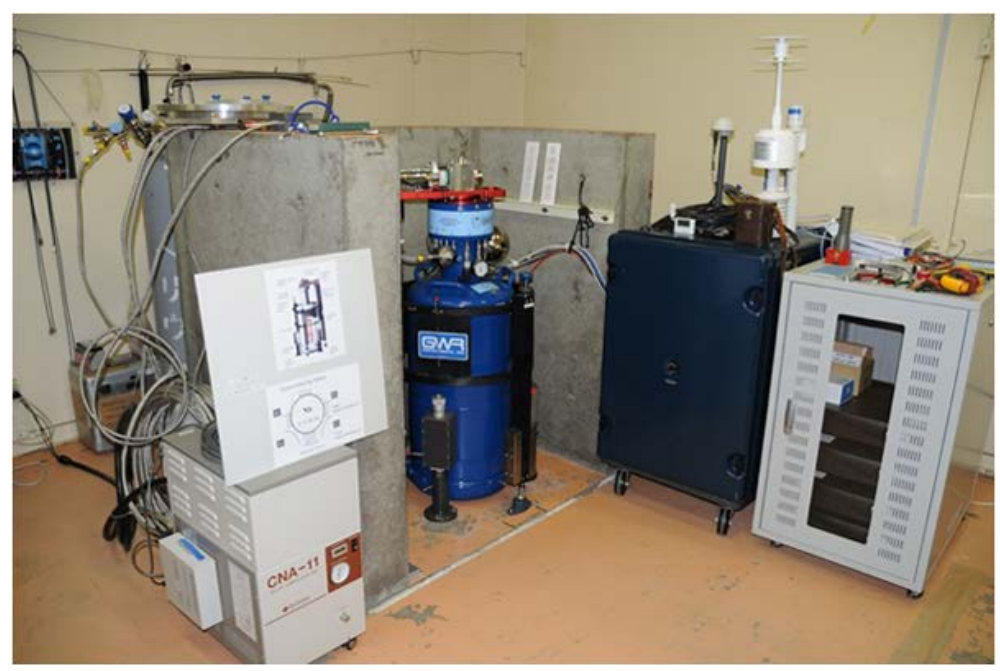

Figure 6. Overview of the OSG\#058.

\section{Status Monitoring of OSG\#058}

The OSG\#058 SG observations can be monitored at any time via its control PC at the Geoscience Laboratory by accessing the Local Area Network (LAN) in Syowa Station. Temperatures at two points along the coldhead, one at the bottom of the first stage and the other at the bottom of the second stage (see Figure 7(a)), as well as other information to diagnose the state of the $4 \mathrm{~K}$ refrigerator, such as inner pressure at the gravimeter neck, can be checked by transferring a screen image of the control PC (see Figure 7(b)). The appearance of the whole system can also be checked by viewing a web camera installed in the GOH.

\section{Data Transfer}

The data acquisition system of the OSG\#058 is equipped with an Internet link. The SG data are sent to the NIPR by FTP protocol via an Intelsat satellite communication link. The network can provide NIPR with daily raw gravity data (>100 MB) from Syowa Station. The data acquired daily since January 7, 2010 can be viewed online [12]. A representative daily monitor plot showing 13 selected components (from August 1, 2011) is given in Figure 8. We can remotely diagnose current status of the SG from these plots. When an oscillation event appears in the gravity signals as seen at around $1 \mathrm{~h} \mathrm{UT}$ in Figure 8, we can also check the occurrence of a distant earthquake in a quasi-real time. In the case of a significant earthquake occurrence, we restrict to enter the GOH to prevent contamination due to artificial noises.

\section{Quality of Gravity Data from OSG\#058}

The OSG\#058 gravity data from January 7, 2010 through June 22, 2011 were analyzed using the BAYTAP-G program [15]. Figure 9 shows the decomposed time series of the (a) original, (b) short-period tides ( $<1$ day), (c) trends including longer-period tides, (d) responses to atmospheric pressure variation, and (e) irregularities (noise). Note that the level of irregular noise was within $\pm 0.1 \mu \mathrm{Gal}$. No significant instrumental drift has yet emerged in the trend record (Figure 9(c)).

The BAYTAP-G analysis gave us the tidal parameters listed in Table 1 for the diurnal and semidiurnal waves. For periods longer than a day, we can obtain amplitudes and phase lags from the extracted trend (Figure 9(c)) by applying a long-period tidal analysis version of BAYTAP-G, called BAYTAP-L; the results are shown in Table 2. The "Amplitude" columns in Table 1 and Table 2 give the amplitude of each tidal wave obtained by the tidal analysis. The "Phase" column shows the phase lag from the theoretically predicted tidal wave for a rigid earth, and the "Factor" column lists the ratio of the amplitude to the theoretical tidal wave.

\section{Data Accessibility}

Data from TT-70\#016 at 1 min intervals have already been released by ISDC, GFZ-Potsdam [11]. 


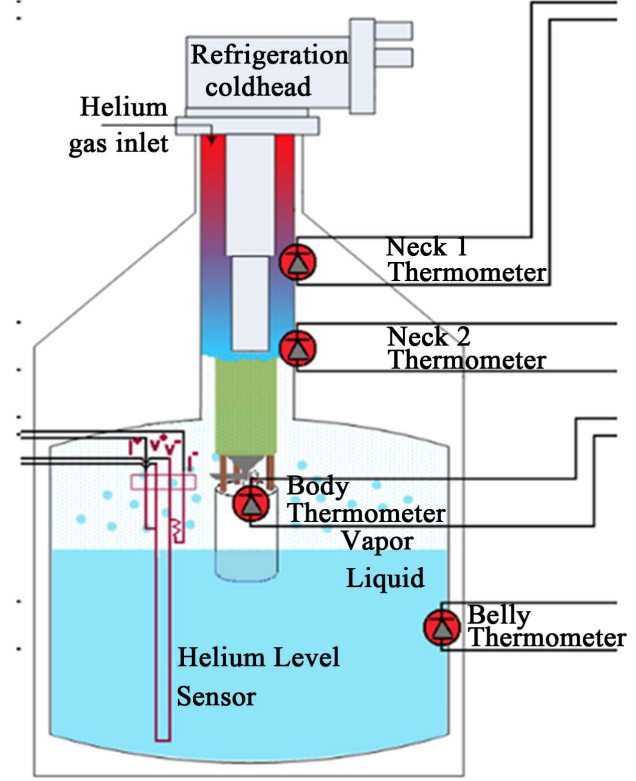

(a)

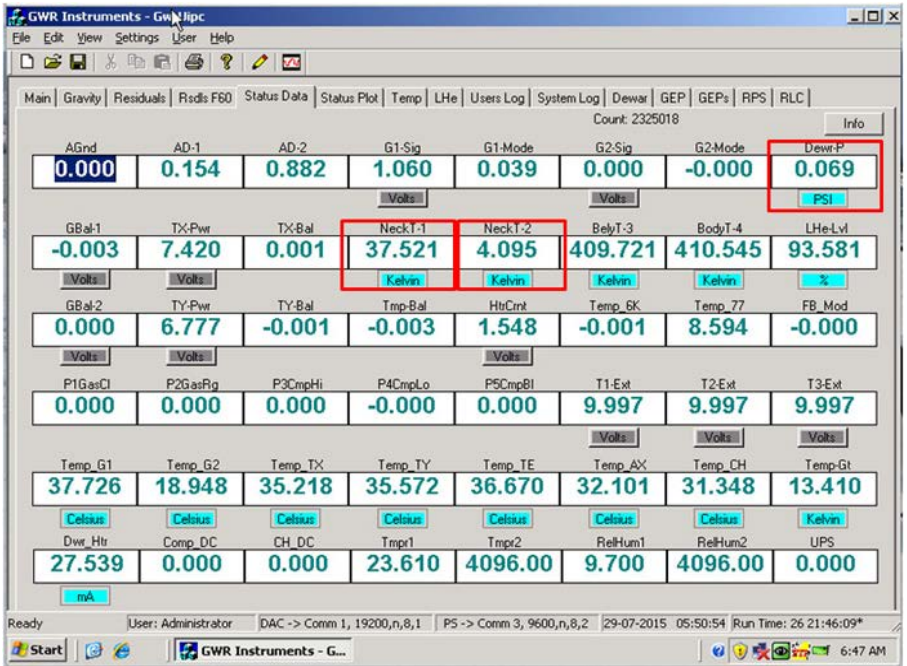

(b)

Figure 7. (a) Cross-section diagram of the OSG\#058 and locations of the neck thermometers; (b) Screen image of the control PC to show the status of the SG. Red rectangles indicate the dewar pressure, neck temperature 1, and neck temperature 2 (see Figure 7(a)).

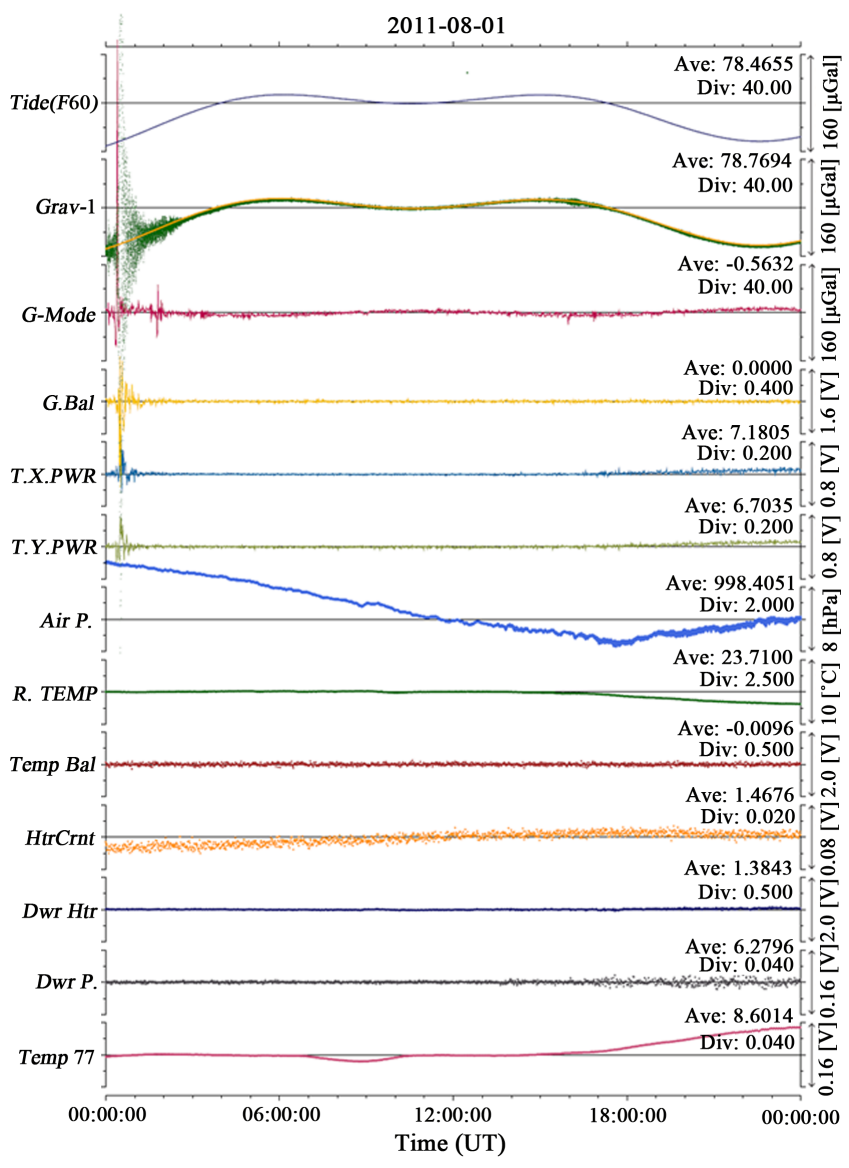

Figure 8. Example of observed data. 
(a)

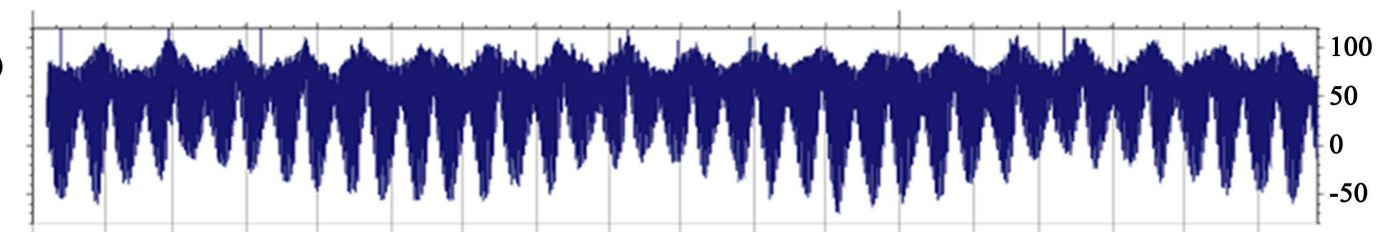

(b)

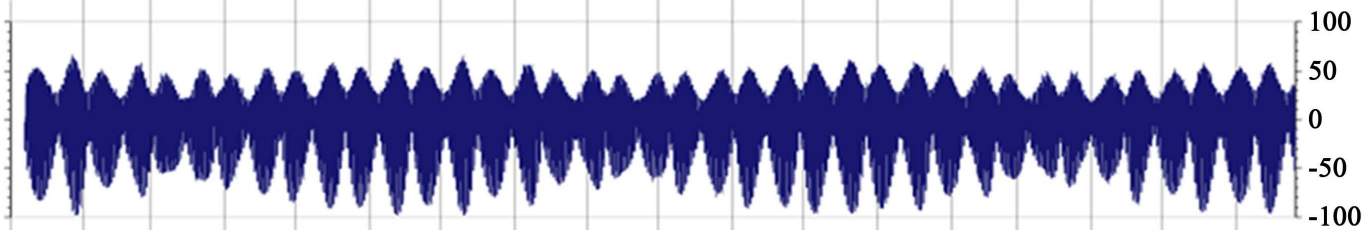

(c)

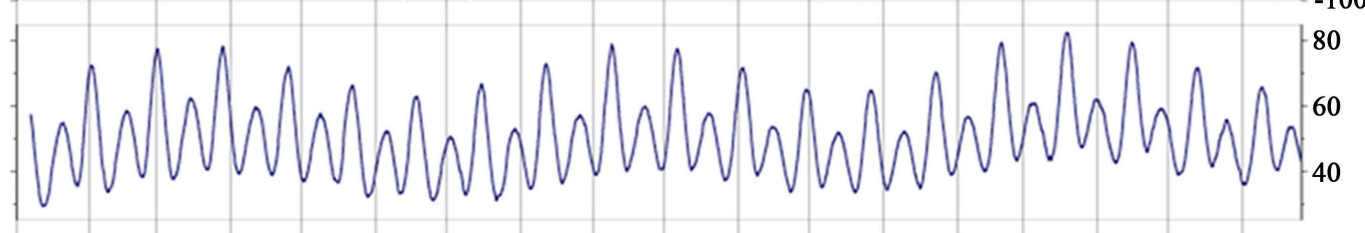

(d)

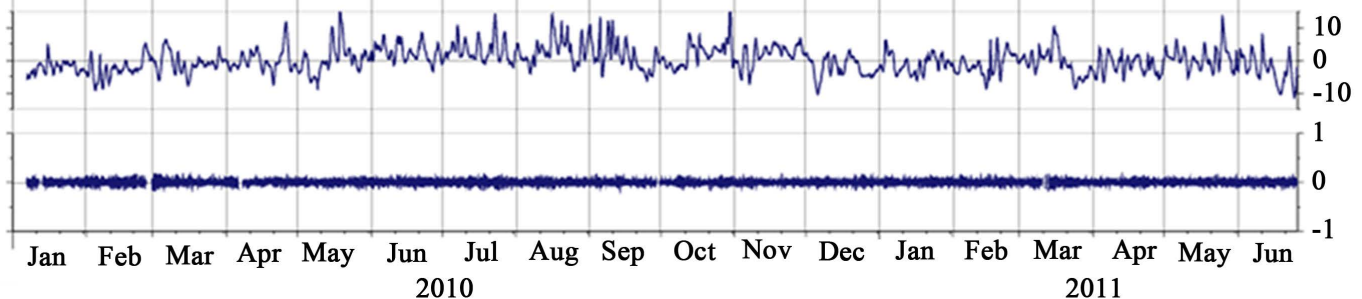

Figure 9. Decomposition of the original record into four components: (a) original record; (b) tidal variation; (c) trend; (d) response to atmospheric pressure change; and (e) irregular (noise) component. Unit: $\mu \mathrm{Gal}$.

Table 1. Result of tidal analysis for short-period tides.

\begin{tabular}{cccc}
\hline Wave & Factor (RMSE) & Phase (RMSE) Unit: degree & Amplitude (RMSE) Unit: $\mu$ Gal \\
\hline Q1 & $1.30267(0.00216)$ & $2.201(0.095)$ & $5.189(0.009)$ \\
O1 & $1.27482(0.00040)$ & $0.779(0.018)$ & $0.779(0.018)$ \\
M1 & $1.24987(0.00333)$ & $0.357(0.152)$ & $2.045(0.005)$ \\
$\pi 1$ & $1.23623(0.01300)$ & $-0.297(0.603)$ & $0.700(0.007)$ \\
P1 & $1.22021(0.00080)$ & $0.169(0.038)$ & $11.812(0.008)$ \\
S1 & $1.21104(0.03134)$ & $3.907(1.483)$ & $0.277(0.007)$ \\
K1 & $1.20563(0.00025)$ & $0.204(0.012)$ & $35.276(0.007)$ \\
$\psi 1$ & $1.25043(0.02566)$ & $0.476(1.176)$ & $0.286(0.006)$ \\
$\varphi 1$ & $1.21822(0.01607)$ & $0.733(0.756)$ & $0.508(0.007)$ \\
J1 & $1.20201(0.00400)$ & $0.555(0.191)$ & $1.967(0.007)$ \\
OO1 & $1.20841(0.00532)$ & $1.769(0.252)$ & $1.082(0.005)$ \\
2N2 & $1.31468(0.00573)$ & $6.159(0.250)$ & $0.322(0.001)$ \\
N2 & $1.44899(0.00118)$ & $1.268(0.047)$ & $2.678(0.002)$ \\
M2 & $1.40605(0.00022)$ & $0.785(0.009)$ & $13.574(0.002)$ \\
$\lambda 2$ & $1.42775(0.02368)$ & $1.980(0.950)$ & $0.102(0.002)$ \\
L2 & $1.45481(0.00641)$ & $-1.170(0.252)$ & $0.397(0.002)$ \\
T2 & $1.50865(0.00776)$ & $2.384(0.295)$ & $0.396(0.002)$ \\
S2 & $1.50495(0.00046)$ & $-1.113(0.018)$ & $6.760(0.002)$ \\
K2 & $1.52099(0.01580)$ & $-0.435(0.059)$ & $1.857(0.002)$ \\
M3 & $1.11082(0.01650)$ & $-19.097(0.850)$ & $0.076(0.001)$ \\
\hline
\end{tabular}

Data period: Jan. 7, 2010-Jun. 26, 2011; Standard deviation $=0.0570 \mu$ Gal; Response coefficient for atmospheric pressure $=-0.359672 \pm 0.002218$ $\mu \mathrm{Gal} / \mathrm{hPa}$. 
All data observed by all three SGs up to December 31, 2012 are available from the NIPR site [12]. Subsequent data, from January, 12013 will be released soon, after a two-year priority period for the registered collaborative researchers of NIPR.

The data are published in ASCII format, with data names in the first line of a daily file, making the data easily identifiable for use. Each daily file is stored in the NIPR archive site after being compressed. We indicate the data names stored in a daily file in Appendix 1 for the datasets of the three SGs.

\section{Summary}

We described the history of observation by three generations of SG at the Syowa Station, Antarctica. The scale factors, noise levels, drift rates, and cryocooling systems of the SGs are listed in Table 3. The bibliography in Appendix 2 lists the scientific publications that have made use of the data.

For the currently operating OSG\#058 SG, the temperatures at two stages of the coldhead along with the inner pressure at the dewar's neck can be monitored remotely to diagnose the condition of refrigerating system. This status can be checked in Japan through an Intelsat data communication link.

Data from March 1993 to December 2009 acquired by the TT70\#016 are available from the ISDC site, while data from the CT\#043 and OSG\#058 are published on a site managed by NIPR. The continuous long-range time series of gravity must contribute to investigating various solid earth dynamics as well as interactions between solid earth and earth's fluid.

\section{Acknowledgements}

We thank all expedition members responsible for ensuring the operation of SG at Syowa Station for more than 20 years, including Tadahiro Sato, who installed the first SG (TT70\#016) in the GOH. Part of the software used

Table 2. Result of tidal analysis for long-period tides.

\begin{tabular}{cccc}
\hline Wave & Factor (RMSE) & Phase (RMSE) Unit: degree & Amplitude (RMSE) Unit: $\mu$ Gal \\
\hline SSA & $1.1197(0.0864)$ & $0.87(4.41)$ & $5.4070(0.4170)$ \\
MSM & $1.1198(0.0788)$ & $0.87(4.03)$ & $1.1740(0.0827)$ \\
MM & $1.1199(0.0706)$ & $0.87(3.60)$ & $6.1395(0.3869)$ \\
MSF & $1.1200(0.0615)$ & $0.88(3.14)$ & $1.0184(0.0559)$ \\
MF & $1.1200(0.0508)$ & $0.87(2.59)$ & $0.4223(0.0219)$ \\
MSTM & $1.1191(0.0580)$ & $0.85(2.97)$ & $2.2209(0.1262)$ \\
MTM & $1.1178(0.0635)$ & $0.81(3.25)$ & $0.3541(0.0228)$ \\
MSQM & $1.1159(0.0719)$ & $0.80(3.69)$ & $0.2931(0.0210)$ \\
MQM & $1.1146(0.0797)$ & $0.78(4.10)$ & $0.0855(0.0067)$ \\
\hline 4-5 Days & $1.1143(0.0871)$ & $0.75(4.48)$ & \\
\hline
\end{tabular}

Data period: Jan. 7, 2010-Jun. 26, 2011; Standard Deviation $=0.0352 \mu \mathrm{Gal}$.

Table 3. Comparison of characteristics of the observed data by the three SGs.

\begin{tabular}{cccccc}
\hline Gravimeter & Data period & Scale factor $(\mu \mathrm{Gal} / \mathrm{volt})$ & Noise level $(\mu \mathrm{Gal})$ & Drift rate $(\mu \mathrm{Gal} /$ year $)$ & Cryocooler \\
\hline TT-70 \#016 & $1993.4-2003.11$ & $-58.165 \pm 0.061$ & \pm 3 & -15 & APS DE202NF \\
CT \#043 & $2003.12-2009.12$ & $-59.461 \pm 0.079$ & \pm 1 & 239 & Leybold 4.2LAB \\
OSG \#058 & $2010.01-$ & $-73.8226 \pm 0.053$ & \pm 0.2 & $< \pm 5$ & SHI SDRK 101 \\
\hline
\end{tabular}


to acquire data from the TT70\#016 and CT\#043 was developed by Yoshiaki Tamura. This research was a part of the Science Program of the Japanese Antarctic Research Expedition (JARE), supported by National Institute of Polar Research (NIPR) and Ministry of Education, Culture, Sports, Science and Technology (MEXT). The publication of this paper is supported by NIPR publication subsidy.

\section{References}

[1] Prothero, W.A. and Goodkind, J.M. (1968) A Superconducting Gravimeter. Review of Scientific Instruments, 39, 12571262. http://dx.doi.org/10.1063/1.1683645

[2] Goodkind, J.M. (1991) The Superconducting Gravimeters: Principles of Operation, Current Performance and Future prospects. In: C. Poitevin, Ed., Cahiers du Centre Europeen de Geodynamique et de Seismologie, Proceedings of the Workshop: Non Tidal Gravity Changes-Intercomparison between Absolute and Superconducting Gravimeters, Walferdange (Grand Duchy of Luxemburg), 3, 81-90.

[3] Warburton, R.J. and Brinton, E.W. (1994) Recent Developments in GWR Instruments' Superconducting Gravimeters. Cahiers du Centre Europeen de Geodynamique et de Seismologie. Proceedings of the 2nd Workshop: Non Tidal Gravity Changes-Intercomparison between Absolute and Superconducting Gravimeters, Walferdange (Grand Duchy of Luxemburg), 11, 23-56.

[4] Boedecker, G. and Fritzer, T. (1986) International Absolute Gravity Basestation Network, Status Report March 1986. International Association of Geodesy Special Study Group 3.87, Veröffentlichungen der Bayerischen Kommission für die Internationale Erdmessung der Bayerischen Akademie der Wissenshaften, Heft, 47, 68 p.

[5] Nakagawa, I., Shibuya, K., Kaminuma, K., Fujiwara, S., Watanabe, K., Murakami, M., Ishihara, M., Tsubokawa, T., Hanada, H. and Yokoyama, K. (1994) Absolute Gravity Measurements at Syowa Station during the Japanese Antarctic Research Expeditions. Bull d'Inform. BGI, 75, 41-56.

[6] Crossley, D., Hinderer, J., Casula, G., Francis, O., Hsu, H.-T., lmanishi, Y., Jentzsch, G., Kadridnen, J., Merriam, J., Meurers, B., Neumeyer, J. Richter, B., Shibuya, K., Sato, T. and van Dam, T. (1999) Network of Superconducting Gravimeters Benefits a Number of Disciplines. Eos, Transactions American Geophysical Union, 80, 121-126. http://dx.doi.org/10.1029/99EO00079

[7] Aoyama, Y., Doi, K., Shibuya, K., Ueda, I. and Fukuzaki, Y. (2015) Contribution of DORIS to GGOS. Abstract of Japan Geoscience Union Meeting 2015, Chiba. http://www2.jpgu.org/meeting/2015/session/PDF/S-GD22/SGD22-13 E.pdf

[8] Iwano, S., Kimura, I. and Fukuda, Y. (2003) Calibration of the Superconducting Gravimeter TT70 \#016 at Syowa Station by Parallel Observation with the Absolute Gravimeter FG5 \#203. Polar Geoscience, 16, 22-28.

[9] Iwano, S. and Fukuda, Y. (2004) Superconducting Gravimeter Observations without a Tilt Compensation System. Physics of the Earth and Planetary Interiors, 147, 343-351. http://dx.doi.org/10.1016/j.pepi.2004.08.001

[10] Shibuya, K., Doi, K., Sato, T. and Tamura, Y. (2005) Syowa Superconducting Gravimeter Raw Data and Associated Expedition Reports (Explanatory CD-ROM). JARE Data Reports, 283 (Earth Science 6), 34 p.

[11] http://isdc.gfz-potsdam.de/index.php?module=pagesetter\&func=viewpub\&tid=1\&pid=55

[12] http://geo.nipr.ac.jp/SG/SG at SYOWA.html

[13] Ikeda, H., Doi, K., Fukuda, Y., Tamura, Y. and Shibuya, K. (2005) Installation of the Superconducting Gravimeter CT (\#043) at Syowa Station, Antarctica. Polar Geoscience, 18, 49-57.

[14] Ikeda, H., Doi, K., Fukuda, Y., Shibuya, K. and Yoshizaki, R., (2005) Installation of Superconducting Gravimeter in Antarctica. Physica C, 426, 759-763. http://dx.doi.org/10.1016/j.physc.2005.02.078

[15] Tamura, Y., Sato, T., Ooe, M. and Ishiguro, M. (1991) A Procedure for Tidal Analysis with a Bayesian Information Criterion. Geophysical Journal International, 104, 507-516. http://dx.doi.org/10.1111/j.1365-246X.1991.tb05697.x

[16] Ikeda, H., Aoyama, Y., Hayakawa, H., Doi, K. and Shibuya, K. (2011) Development of the Superconducting Gravimeter Using a New Type of Diaphragm. Physica C, 471, 1543-1546. http://dx.doi.org/10.1016/j.physc.2011.05.234

[17] GGP (1997) GGP Newsletter \#5, Sept. 10, 1997. Crossley, D. and Hinderer, J., Eds.

[18] Doi, K., Shibuya, K., Ikeda, H. and Fukuda, Y. (2008) Continuous Gravity Observation with the Superconducting Gravimeter CT\#043 at Syowa Station, Antarctica. In: Capra, A. and Dietrich, R., Eds., Geodetic and Geophysical Observations in Antarctica, an Overview in the IPY Perspective, Springer, Berlin Heiderberg, 237-247.

[19] Aoyama, Y., Doi, K., Ikeda, H., Shibuya, K. and Hayakawa, H. (2015) Gravitational Effect of Accumulated Snow Mass in Five-Year Continuous Gravity Data Obtained with Superconducting Gravimeter OSG\#058 at Syowa Station, East Antarctica. Submitted to Polar Science.

[20] http://www.gwrinstruments.com/ 


\section{Appendix 1. Data Names for Each SG in the Archived File}

1) TT70\#016 data with 2 s sampling interval (August 1993-December 1999)

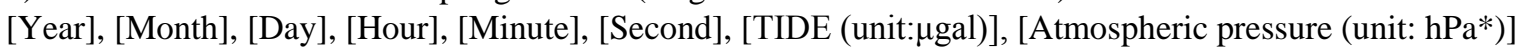

*Actual atmospheric pressure value is calculated from the stored value by the following formulae depending on the stored value:

$\mathrm{P}(\mathrm{hPa})=[$ Atmospheric pressure $]+880$ (if [Atmospheric pressure $] \geq 60)$,

$\mathrm{P}(\mathrm{hPa})=[$ Atmospheric pressure $]+960$ (if [Atmospheric pressure $] \leq 60)$.

2) TT70\#016 data with $1 \mathrm{~s}$ sampling interval (April 1999-November 2003)

[Year], [Month], [Day], [Hour], [Minute], [Second], [GGP1(unit: $\mu$ Gal)], [TIDE (unit: $\mu$ Gal)], [Atmospheric pressure (unit: hPa)]

3) СT\#043 data

[Year], [Month], [Day], [Hour], [Minute], [Second], [TIDE (unit: $\mu$ Gal)], [GGP1 (unit: $\mu$ Gal)], [Atmospheric pressure (unit: hPa)], [Tilt X PWR (unit: V)], [Tilt Y PWR (unit: V)]

4) OSG\#058 data

[Year], [Month], [Day], [Hour], [Minute], [Second], [TIDE (unit: $\mu$ Gal)], [GGP1 (unit: $\mu$ Gal)], [Atmospheric pressure (unit: hPa)], [Tilt X PWR (unit: voltage)], [Tilt Y PWR (unit: V)]

\section{Appendix 2. Bibliography}

[1] Doi, K., Shibuya, K., Aoyama, Y., Ikeda, H. and Fukuda, Y. (2010) Observed Gravity Change at Syowa Station Induced by Antarctic Ice Sheet Mass Change. In: Stelios, M., Ed., Gravity, Geoid and Earth Observation, IAG Symposia, Springer, Berlin Heiderberg, 135, 557-562.

[2] Iwano, S., Fukuda, Y., Sato, T., Tamura, Y., Matsumoto, K. and Shibuya, K. (2005) Long-Period Tidal Factors at Antarctica Syowa Station Determined from 10 Years of Superconducting Gravimeter Data. Journal of Geophysical Research, 110, Article ID: B10403.

[3] Kim, T.-H., Shibuya, K., Doi, K., Aoyama, K. and Hayakawa, H. (2011) Validation of Global Ocean Tide Models Using the Superconducting Gravimeter Data at Syowa Station, Antarctica, and In-Situ Tide Gauge and Bottom Pressure Observations. Polar Science, 5, 21-39.

[4] Kim, T.-H. and Shibuya, K. (2013) Verification of the Ellipsoidal Earth Model with an Inelastic and Convective Mantle Using Tidal Gravity Variations Revisited. Geophysical Journal International, 194, 230248.

[5] Nawa, K., Suda, N., Fukao, Y., Sato, T., Aoyama, Y. and K. Shibuya (1998) Incessant Excitation of the Earth's Free Oscillations. Earth, Planets Space, 50, 3-8.

[6] Sato, T., Shibuya, K., Nawa, K., Matsumoto, K. and Tamura, Y. (1996) On the Diurnal and Semidiurnal Tidal Factors at Syowa Station, Antarctica. The Geodetic Society of Japan, 42, 145-153.

[7] Sato, T., Nawa, K., Shibuya, K., Tamura, Y., Ooe, M. and Kaminuma, K. (1997) Long-Period Tides Observed with a Superconducting Gravimeter at Syowa Station, and Their Implications to Global Ocean Tide Modeling. Physics of the Earth and Planetary Interiors, 103, 39-53.

[8] Sato, T., Nawa, K., Shibuya, K., Tamura, Y., Ooe, M., Kaminuma, K. and Aoyama, Y. (1997) Polar Motion Effect on Gravity Observed with a Superconducting Gravimeter at Syowa Station, Antarctica. In: Segawa, J., et al., Eds., International Association of Geodesy Symposia, Gravity, Geoid and Marine Geodesy, Springer-Verlag, Berlin, 117, 99-106. 